\title{
On the Relationship between Propositional and Doxastic Justification
}

\author{
Forthcoming in Philosophy and Phenomenological Research \\ John Turri \\ john.turri@gmail.com
}

\begin{abstract}
I argue against the orthodox view of the relationship between propositional and doxastic justification. The view under criticism is: if $p$ is propositionally justified for $\mathrm{S}$ in virtue of S's having reason(s) R, and S believes $p$ on the basis of $\mathrm{R}$, then S's belief that $p$ is doxastically justified. I then propose and evaluate alternative accounts of the relationship between propositional and doxastic justification, and conclude that we should explain propositional justification in terms of doxastic justification. If correct, this proposal would constitute a significant advance in our understanding of the sources of epistemic justification.
\end{abstract}

\section{The Orthodox View}

Imagine two jurors, Miss Knowit and Miss Not, deliberating about the case of Mr.

Mansour. Both jurors have paid close attention throughout the trial. As a result, both have good reason to believe that Mansour is guilty. Each juror goes on to form the belief that Mansour is guilty, which he in fact is. Miss Knowit believes he's guilty because of the evidence presented during the trial. Miss Not believes he's guilty because he looks suspicious. Miss Knowit knows that Mansour is guilty; Miss Not does not. Why the difference? Miss Knowit believes he's guilty on the basis of the good reasons she has, whereas Miss Not, despite having good reasons at her disposal, believes based on mere suspicion.

The basing relation, according to a widespread and influential line of thought, is what distinguishes doxastic from propositional justification. (Some put the distinction in terms of "justifiable" versus "justified" belief, and we might also put it in terms of "being in a position to justifiedly believe" versus "justifiedly believing.") In virtue of having a good reason to believe the defendant guilty, the proposition $<$ Mansour is guilty $>$ is propo- 
sitionally justified for both jurors, and because Miss Knowit's belief is based on the good reasons she has, her belief is doxastically justified or well founded. Knowledge requires doxastic, not merely propositional, justification, which explains why Miss Knowit but not Miss Not knows Mansour is guilty. Believing for a good reason is a valuable state, a greater achievement than merely having a good reason you fail to properly utilize.

Reflecting on such cases might easily lead you to adopt the following thesis: if $p$ is propositionally justified for $\mathrm{S}$ in virtue of S's having reason(s) R, and $\mathrm{S}$ believes $p$ on the basis of $\mathrm{R}$, then $\mathrm{S}$ 's belief that $p$ is doxastically justified. And, indeed, an impressive array of epistemologists adopts just this view. For instance, Jonathan Kvanvig remarks,

Doxastic justification is what you get when you believe something for which you have propositional justification, and you base your belief on that which propositionally justifies it. ${ }^{1}$

According to John Pollock and Joseph Cruz:

To be justified in believing something it is not sufficient merely to have a good reason for believing it. One could have a good reason at one's disposal but never make the connection. [In such a case] what is lacking is that you do not believe the conclusion on the basis of those reasons. ${ }^{2}$

Marshall Swain tells us:

It often happens that a person's belief that $h$ is based upon a set of reasons $R$ when believing that $h$ on the basis of $R$ is not justified for that person. This can happen even though the person has other reasons such that if the belief had been based upon those reasons, then the belief would have been justified. ${ }^{3}$

Keith Korcz claims:

\footnotetext{
${ }^{1}$ Kvanvig (2003: section B1). I should note that Kvanvig at times adds that the belief must be "properly" based in order to count as doxastically justified. But he never explains what "properly" amounts to, and often omits it.

${ }^{2}$ Pollock and Cruz (1999: 35 - 36). Also see Pollock (1986: 36 - 37).

${ }^{3}$ Swain (1979: 25).
} 
A belief is merely justifiable for a person $\mathrm{S}$ when $\mathrm{S}$ possesses reasons which would be sufficient to justify the belief were the belief based on those reasons.... A belief is justified for $\mathrm{S}$ when $\mathrm{S}$ possesses reasons sufficient to justify the belief and has made an appropriate connection between her reasons and her belief. This appropriate connection is the basing relation. ${ }^{4}$

\section{Richard Feldman says,}

S's belief that $p$ at time $t$ is [doxastically] justified (well-founded) iff (i) believing $p$ is justified for $\mathrm{S}$ at $t$; (ii) $\mathrm{S}$ believes $p$ on the basis of evidence that supports $p .^{5}$

William Alston distinguishes between "having adequate grounds" and believing "based on an adequate ground," and claims it is "conceptually true that one is justified in believing that $p$ iff one's belief that $p$ is based on an adequate ground...." ${ }^{96}$ Having adequate grounds and believing on adequate grounds are tantamount to propositional and doxastic justification, respectively.

It is instructive to note that epistemologists say similar things about knowledge. For example, Stewart Cohen, in the course of discussing contextualism and skepticism, considers the following closure principle: If $\mathrm{S}$ knows that $p$, and $\mathrm{S}$ knows that $p$ entails $q$, then $\mathrm{S}$ knows that $q .{ }^{7}$ Cohen then remarks, "Of course, S may not believe $q$ or S may not believe $q$ on the basis of seeing the entailment, but then $\mathrm{S}$ will still be in a position to know $q$. That is, all S has to do to know q is to believe it on the basis of seeing the entailment." ${ }^{8}$ Cohen apparently endorses the view that to know $q$ you need only believe $q$ on the basis of the good reasons you have for $q$ (setting Gettier aside). Our focus is justification, but this should remind us that the lessons learned apply to knowledge as well.

\footnotetext{
${ }^{4}$ Korcz (2000: 525 - 526).

${ }^{5}$ Feldman (2002: 46). See also Feldman (2004: esp. section 1) and Feldman and Conee (1985: section IV).

${ }^{6}$ Alston (1985: 190). Alston expresses the same sentiments in his (2005: 90).

${ }^{7}$ Cohen (1999: 62).

${ }^{8}$ Cohen (1999: 84 n. 14). Emphasis added.
} 


\section{The Orthodox View Refuted}

The orthodox view outlined above is wrong. That is, Basis is false.

(Basis) IF (i) $p$ is propositionally justified for $\mathrm{S}$ in virtue of S's having reason(s) $\mathrm{R}$, and (ii) $\mathrm{S}$ believes $p$ on the basis of $\mathrm{R}$, THEN S's belief that $p$ is doxastically justified.

Before turning to specific examples, we should ask ourselves whether it is plausible to think that the way in which a subject makes use of his reasons matters not to whether his belief is well founded. Basis makes no mention of the way in which the subject performs in forming or sustaining a belief. This is not a minor detail. Nor is it something we can set aside for present purposes, in the hope that the matter will resolve itself within a more comprehensive theory of propositional justification. In evaluating beliefs we are evaluating a kind of performance, the performance of a cognitive agent in representing the world as being a certain way, and when performing with materials (which, in cognitive affairs, will include reasons or evidence), the success, or lack thereof, of one's performance will depend crucially on the way in which one makes use of those materials. This is true for carpentry as well as cognition. Consider a carpenter, equipped with the finest tools and lumber. You want a deck built, and he is in a position to build a wonderful one for you. Despite the quality of his tools and lumber, unless he puts them together in the right way, you are not going to be happy with the end result. You want a well built deck, not just one built with tools and materials fit for making a well built deck. Merely having the right equipment for the job, and using it to perform the job, does not guarantee a job well done. As such, I submit that we should expect there to be compelling counterexamples to Basis that exploit this glaring weakness. 
Ram Neta discusses an example that might at first appear to threaten Basis. ${ }^{9}$ It involves a subject who bases her belief on conclusive reasons (I use "reasons" where Neta uses "evidence"), but does so unreasonably because she ignores relevant counterevidence in the process. A proponent of Basis could respond that possessing relevant counterevidence plausibly precludes propositional justification. Another response would be to distinguish provisional (prima facie) from all-things-considered (ultima facie) propositional justification, and clarify that Basis pertains only to the latter, which requires that the subject not possess relevant counterevidence. Perhaps neither response will ultimately withstand scrutiny, but we can bypass the controversy because examples abound that don't involve subjects ignoring relevant counterevidence.

Let us then turn to the first such example. Consider two of the other jurors, Miss Proper and Miss Improper, sitting in judgment of Mr. Mansour. Each paid close attention throughout the trial. As a result, each knows the following things:

(P1) Mansour had a motive to kill the victim.

(P2) Mansour had previously threatened to kill the victim.

(P3) Multiple eyewitnesses place Mansour at the crime scene.

(P4) Mansour's fingerprints were all over the murder weapon.

$<$ Mansour is guilty $>$ is propositionally justified for both jurors because each knows (P1 P4). ${ }^{10}$ As it happens, each comes to believe $<$ Mansour is guilty $>$ as the result of an episode

${ }^{9}$ Neta (2002: 671). Pryor (2004: 365) considers a similar example and draws a similar lesson.

${ }^{10}$ Must the jurors also believe that $(\mathrm{P} 1-\mathrm{P} 4)$ constitute good evidence to conclude that Mansour is guilty in order for their knowledge of $(\mathrm{P} 1-\mathrm{P} 4)$ to propositionally justify that conclusion for them? No, because that would impose an unacceptably stringent condition on propositional justification. Human children, who may not even possess the concept of evidence, are propositionally justified in believing many things. Lacking the concept of evidence, they cannot so much as entertain the thought that $\mathrm{X}$ is evidence for $\mathrm{Y}$, much less believe such a thing. See also Conee and Feldman (2001: 75 - 76). 
of explicit, conscious reasoning that features $(\mathrm{P} 1-\mathrm{P} 4)$ essentially. Miss Proper reasons like so:

(Proper Reasoning) (P1 - P4) make it overwhelmingly likely that Mansour is guilty. (P1 - P4) are true. Therefore, Mansour is guilty.

Miss Improper, by contrast, reasons like this:

(Improper Reasoning) The tea leaves say that $(\mathrm{P} 1-\mathrm{P} 4)$ make it overwhelmingly likely that Mansour is guilty. (P1 P4) are true. Therefore, Mansour is guilty.

Each juror satisfies conditions (i) and (ii), yet only Miss Proper's belief that Mansour is guilty is doxastically justified. Only Miss Proper is justified in believing as she does that he is guilty. Miss Improper's belief that Mansour is guilty is based on the reasons that propositionally justify $<$ Mansour is guilty $>$ for her, but only in light of the tea-leaf reading, which spoils things. Her belief is improperly based on (P1 - P4), whereas Miss Proper's is properly based.

The same example shows that Basis $^{+}$fails. ${ }^{11}$

(Basis $^{+}$) IF (i) $p$ is propositionally justified for $\mathrm{S}$ in virtue of $\mathrm{S}$ 's having reason(s) $\mathrm{R}$, and (ii) $\mathrm{S}$ believes $p$ on the basis of $\mathrm{R}$ as evidence for $p$, THEN S's belief that $p$ is doxastically justified.

${ }^{11}$ Fairweather (2001: 74 - 75) suggests something like this view. 
Miss Improper does base her belief on $(\mathrm{P} 1-\mathrm{P} 4)$ as evidence for $<$ Mansour is guilty $>$. It is part of the content of her reasoning that $(\mathrm{P} 1-\mathrm{P} 4)$ make $<$ Mansour is guilty $>$ overwhelmingly probable. $^{12}$

Some might object that my example depends on adding to the basis of Miss Improper's belief. ${ }^{13}$ This observation might then naturally lead to a revised principle:

(Austere Basis) IF (i) $p$ is propositionally justified for $\mathrm{S}$ in virtue of S's having reason(s) $\mathrm{R}$, and (ii) $\mathrm{S}$ believes $p$ on the basis of R and only R, THEN S's belief that $p$ is doxastically justified.

Austere Basis has extremely limited application. How often do we believe something for only those reasons that propositionally justify it for us? It's trifling even if true. It also gives the wrong verdict in the following case.

Mr. Ponens and Mr. F.A. Lacy each knows the following things:

(P5) The Spurs will win if they play the Pistons.

(P6) The Spurs will play the Pistons.

This is a paradigm case of propositional justification. $<$ The Spurs will win $>$ is propositionally justified for each man because he knows (P5) and (P6). This satisfies clause (i). From these two premises, and only these premises, each man draws the conclusion:

(P7) Therefore, the Spurs will win.

This satisfies clause (ii). But the devil is in the details. Ponens applies modus ponens to reach the conclusion. Lacy, however, applies a different inference rule, which we may call ${ }^{12}$ If it's not obvious that the content of her reasoning as described fits the bill, we can modify the case accordingly.

${ }^{13}$ Thanks to Juan Comesaña for conversation on this point. 
modus profusus: for any $p, q$, and $r:(p \wedge q) \rightarrow r$. Lacy's belief that the Spurs will win is definitely not doxastically justified; following that rule could never lead to a justified belief. This is a counterexample to Austere Basis. It also works against Basis.

So there are powerful counterexamples to Basis and company. But the problem goes deeper than mere counterexamples. As noted earlier, Basis misses something deep and important about the relationship between propositional and doxastic justification. The way in which the subject performs, the manner in which she makes use of her reasons fundamentally determines whether her belief is doxastically justified. Poor utilization of even the best reasons for believing $p$ will prevent you from justifiedly believing or knowing that $p$.

I want to emphasize two further points about the discussion of Basis and its ilk. First, the intuitions about the counterexamples do not rely on any particular theory of the epistemic basing relation. It matters not to the examples whether the belief is based on the reasons in virtue of the reasons causing the belief, or whether the belief is based on the reasons in virtue of the subject having an evidential belief to the effect that the reasons in question are indeed good reasons to accept the conclusion, or whether the basing relation obtains in virtue of both the reason causing the belief and the subject having the evidential belief. To demonstrate this, notice that in the case of Ponens and Lacy, we can add these details arbitrarily and it does not affect the intuition that Ponens' belief in the conclusion is doxastically justified whereas Lacy's belief is not. I stipulate that Ponens' belief in (P7) is (non-deviantly) caused by his belief in (P5) and (P6), and the same is true of Lacy; I also stipulate that Ponens believes that the conjunction of (P5) and (P6) constitutes an impecca- 
bly good reason to believe (P7), and the same is true of Lacy. None of this affects the intuition that Ponens' belief is doxastically justified, whereas Lacy's belief definitely is not.

Second, and closely related to the first point, neither the thesis being argued for here, nor the examples offered in support of it, have anything to do with the "Gypsylawyer" cases that often feature prominently in discussions involving the epistemic basing relation. Gypsy-lawyer cases — so called because the original case in this genre, due to Keith Lehrer, featured a "Gypsy lawyer"14_ are put forward as purported counterexamples to causal theories of the epistemic basing relation, the upshot supposedly being that a belief need not be caused by a reason in order to be based on that reason. Even if this were granted, it would not, of course, impugn the view that certain kinds of causation are sufficient to establish a basing relation, a point Lehrer himself recognizes. ${ }^{15}$ Nothing in the examples offered here requires us to take a stand on the merit of Gypsy-lawyer cases or the view that causation is necessary for basing. And the claim that Basis and its ilk are false quite obviously bears no relation to whether causation is necessary for basing.

That should suffice to quell suspicions that my discussion somehow smuggles in controversial assumptions regarding the basing relation. However, out of an abundance of caution, I will briefly explain the anatomy of Gypsy-lawyer cases, so that even those readers inordinately concerned with such cases may satisfy themselves that the present discussion is orthogonal to the issues at stake in Gypsy-lawyer cases. (Those who harbor no such suspicions may simply skip the rest of this paragraph.) Gypsy-lawyer cases all share the same basic structure. ${ }^{16}$ At time $t, \mathrm{~S}$ has a true belief that $p$, completely causally

${ }^{14}$ Lehrer (1971).

${ }^{15}$ Lehrer (1990: 169).

${ }^{16}$ See, e.g., Korcz (2000: 528 - 532), Lehrer (1971; 1990: 169), Pappas (1979: 57 - 58), and Harman (1973: $31-32)$, all of whom offer their own variants. Sometimes the case is pitched in terms of knowledge, other times in terms of doxastic justification. 
sustained by inadequate reason $\mathrm{R}$. S believes $p$ as strongly as he possible can. $\mathrm{S}$ obviously does not know $p$. At some subsequent time $t^{\prime}, \mathrm{S}$ acquires reason $\mathrm{R}^{*}$, which is an adequate reason to believe $p$. S explicitly recognizes that $\mathrm{R}^{*}$ is an adequate reason to believe $p$. Nevertheless, R continues to fully causally sustain $\mathrm{S}^{\prime}$ s belief, and $\mathrm{R}^{*}$ in no way contributes. Yet it is (supposedly) intuitively obvious that $\mathrm{S}$ comes to know $p$ at $t^{\prime}$. S could know $p$ only if his belief was based on adequate reasons, and ex hypothesi $\mathrm{R} *$ is the only adequate reason $\mathrm{S}$ has, thus it follows that his belief comes to be based on $\mathrm{R}^{*}$. But S's belief is causally independent of $\mathrm{R}^{*}$, so a belief need not be caused by a reason in order to be based on that reason. As should be plain, the issues raised by this sort of case bear no relation to the main points I am concerned to make in this paper.

\section{III.Alternative Proposals}

It is standardly assumed that there is some deep and important relationship between propositional and doxastic justification. One might disagree, taking the position that they are only tenuously related, or even totally independent of one another. Nevertheless, I find the standard assumption plausible, and will adopt it as my own.

Doxastic justification cannot be understood simply as propositional justification plus basing. What, then, is the relationship between propositional and doxastic justification? Rather than try to understand doxastic justification in terms of propositional justification, perhaps a different approach is in order. In proceeding, we must keep in mind that any account of the relationship will be sorely lacking if it neglects the crucial role of the proper, competent use of reasons. It would be completely unsurprising if we were unable to state individually necessary and jointly sufficient conditions for propositional justification. Nev- 
ertheless, I propose that we can make progress in understanding that concept along the following lines.

(PJ) Necessarily, for all $\mathrm{S}, p$, and $t$, if $p$ is propositionally justified for $\mathrm{S}$ at $t$, then $p$ is propositionally justified for $\mathrm{S}$ at $t$ BECAUSE S currently possesses at least one means of coming to believe $p$ such that, were $\mathrm{S}$ to believe $p$ in one of those ways, S's belief would thereby be doxastically justified. ${ }^{17,} 18$

In a word, the subject's intellectual abilities explain why she is in a position to justifiedly believe or know $p .{ }^{19}$

PJ should command our attention for several reasons. First, because it provides an illuminating explanation of what goes on in paradigm cases of propositional justification. Recall the case of Messrs Ponens and Lacy. Each of them knows things that would lead any normal human adult competently to arrive, by a straightforward application of modus ponens, at the conclusion that the Spurs will win. Miss Proper and Miss Improper are as capable as any other normal human adult of competent explanatory reasoning, and each

${ }^{17}$ Strictly speaking, it should read 'believing $p$ ' rather than 'coming to believe $p$ '. If your belief that $p$ is doxastically justified, then $p$ is propositionally justified for you, even if you don't presently have a means of coming to believe $p$, as would perhaps be the case if you already believed it. This minor point doesn't alter the basic proposal, so to simplify the discussion I shall stick with the formulation in the text.

${ }^{18}$ Compare Goldman's (1979: 351 - 352) definition of ex ante justification in terms of ex post justification: "Person $\mathrm{S}$ is ex ante justified in believing $p$ at $t$ if and only if there is a reliable belief-forming operation available to $\mathrm{S}$ which is such that if $\mathrm{S}$ applied that operation to this total cognitive state at $t, \mathrm{~S}$ would believe $p$ at $t$-plus-delta (for a suitably small delta) and that belief would be ex post justified." As Goldman (1979: 353 n. 17) himself notes, the ex antelex post distinction is closely related to the propositional/doxastic distinction we've been discussing. I do not, whereas Goldman does, attempt to state necessary and sufficient conditions.

${ }^{19}$ Compare Sosa's (2003: ch. 7, esp. pp. $127-8,134$, and 138) discussion of the speckled hen and related issues, as well as his (2004: 287 - 290) response to Richard Feldman. Also relevant here are Greco (1999) and (forthcoming). 
knows things, regarding which by far the most plausible explanation is the guilt of Mansour.

Second, because PJ provides a model for understanding how non-reason-based doxastically-justified belief and knowledge is possible. It would provide for non-reasonbased doxastically-justified belief if one could competently acquire or sustain belief in some proposition without doing so on the basis of a reason. I submit that the belief in one's own existence is like this. ${ }^{20}$ Descartes notwithstanding, it is highly implausible that I need a reason to justifiedly believe, or know, for that matter, that I exist. Of course, the fact that I have abundant reasons to believe that I exist is irrelevant to whether I need such reasons for my belief in my own existence to rise to the level of doxastic justification or knowledge. Let me be clear: I am not suggesting that the epistemic status of these cogito beliefs is somehow in question. They obviously possess epistemic status par excellence-that is an unquestionable datum, to which theory is answerable. My point is that $\mathbf{P J}$ helps us better understand an important dimension of their epistemic status, and this is a virtue of the theory.

Third, because PJ withstands a spate of initially compelling objections. One initially compelling objection to $\mathbf{P J}$ stems from the thought that certain propositions can be propositionally justified for you, but coming to believe them would destroy the evidence you had for them, guaranteeing a doxastically unjustified belief. ${ }^{21}$ Suppose Sanders is learning about physics. He is reflective enough to know that he has considered only the Newtonian concept of force, defined as mass times acceleration. Intuitively, $<$ I have never considered the proposition that force equals mass divided by acceleration $>$ is proposition-

${ }^{20}$ Some memory beliefs (beliefs "based on memory") may also be like this.

${ }^{21}$ What follows is a modified version of one of Kvanvig's (2003: section B1) cases. 
ally justified for Sanders; after all, he knows something that straightforwardly entails it. Nevertheless, coming to believe it would provide him with conclusive reason to disbelieve it, in which case he could not justifiedly believe it. Thus, says the opponent, PJ cannot do justice to our intuitions in this kind of case.

I am unpersuaded by such examples. The obvious response is that the case is slightly but importantly misdescribed. The proposition that is propositionally justified for Sanders is $<\mathrm{I}$ have never before considered the proposition that force equals mass divided by acceleration>, and obviously Sanders can justifiedly believe that. It is perfectly natural to leave the 'before' implicit in ordinary conversation, and the Sanders example trades on this in order to give the appearance of posing a problem for PJ. Consider: the therapist asks, "Have you ever considered divorcing your husband?" and the woman responds, "I've never so much as entertained the thought." The woman needn't retract her statement were the therapist to continue, "Never, you say? What about just now when I asked? You had to entertain it to understand my question." At most, the woman would clarify, "I of course meant that I had never entertained the thought before you asked about it"- though an icy stare seems a more likely response.

Having dealt with potential counterexamples wherein deliberation destroys evidence, the flip side of that worry may command our attention, to wit, deliberation sometimes creates evidence. ${ }^{22}$ This exploits the vagueness in what it is to "currently possess a means." Suppose a first-year logic student knows the introduction and elimination rules for conjunction and disjunction in a natural deduction system, but he hasn't yet proven either of DeMorgan's Laws. Consider the Law that a negation of a conjunction is equivalent to a disjunction of the negations of the conjuncts: $\neg(p \wedge q) \leftrightarrow(\neg p \vee \neg q)$. He currently pos${ }^{22}$ Thanks to Ernie Sosa for conversation on this point. 
sesses a means such that, were he to employ it, he would come to justifiedly believe that Law. That much seems right. Notice, however, that this implies that, even before he goes through the proof, he possesses a means such that, were he to employ it, he would justifiedly believe $<$ I have proven one of DeMorgan's Laws $>$ : he just needs to go through the proof, reflect on what he just accomplished, and then form the relevant belief in light of that. However, no such thing is propositionally justified for him beforehand.

This would be a problem for the present proposal only if $\mathbf{P J}$ claimed:

IF S currently possesses at least one means of coming to believe $p$ such that were $\mathrm{S}$ to believe $p$ in one of those ways, S's belief would thereby be doxastically justified, THEN $p$ is propositionally justified for $\mathrm{S}$,

which it does not.

Thus, $\mathbf{P J}$ has much to recommend it. But we would be remiss if we failed to note that the following sort of case presents a noteworthy challenge to PJ. Suppose that Ron knows that invading Iran would be catastrophically stupid, and that if invading Iran would be catastrophically stupid, then the U.S. ought not to invade Iran. Intuitively, the proposition $<$ the U.S. ought not to invade Iran $>$ is propositionally justified for Ron. Now we add that Ron is presently incapable of coming to believe that the U.S. ought not to invade Iran. Having listened to right-wing talk radio and watched Fox News for far too long, Ron is simply psychologically incapable of believing that the U.S. ought not to invade any country, much less Iran. Thus, he does not presently have a means of coming to justifiedly believe that the U.S. ought not to invade Iran, because he doesn't have any means of coming 
to believe it. Nevertheless, the intuition persists that $<$ the U.S. ought not to invade Iran $>$ is propositionally justified for him, which now cannot be because of any ability Ron has to competently arrive at that conclusion.

Apparently we are inclined to abstract away from Ron's odd disability regarding the proposition $<$ the U.S. ought not to invade Iran>. Surely Ron is not like this with respect to most propositions, and most of the time he is not even like this with respect to this specific proposition: normally, if he knows that $p$, and knows that $q$ if $p$, then he has the wherewithal to competently reason his way, via an application of modus ponens, to a belief in $q$. And this more general ability, it might plausibly be argued, grounds the intuition that the ' $q$ ' in this case is propositionally justified for Ron, despite his strange circumstances. It might be replied that I have made things too easy on myself. Let's stipulate that Ron suffers from a general disability to reason from knowledge of a conditional and its antecedent, to a belief in its consequent. Don't we still have the intuition that $<$ the U.S. ought not to invade Iran> is propositionally justified for Ron, given what else he knows? My intuition about this version of the case is noticeably less clear than about the previous one. Moreover, I doubt whether we should trust very strongly our intuitions about such a strange case. Conditional reasoning is so fundamental to our intellectual lives that I am hard pressed to make sense of Ron. It would not be unreasonable to respond by granting that knowledge of $p$ and $q$ if $p$ would be a good reason for us to believe $q$, yet deny that it is a good reason for Ron in this case, due to his strange disability. This, I think, is enough to account for any positive intuition we have about Ron's epistemic position vis-à-vis $q$.

But there is a more direct response available. Even lacking facility with conditional reasoning, Ron can easily still competently reason his way to the conclusion via disjunctive 
syllogism. $q$ if $p$ is logically equivalent to either not-p or $q$; given knowledge of $p$, then, it follows straightforwardly by elementary inference that $q$. Thus, even in the more extravagant version of the case, Ron does have a means of justifiedly coming to believe $q$ after all. $^{23}$

Despite success in staving off this challenge to $\mathbf{P J}$, we still might learn an important lesson from cases like Ron's. Hints may also be gleaned from something I said in support of PJ earlier:

PJ should command our attention ... because it provides an illuminating explanation of what goes on in paradigm cases of propositional justification. Recall the case of Messrs Ponens and Lacy. Each of them knows things that would lead any normal human adult competently to arrive, by a straightforward application of modus ponens, at the conclusion that the Spurs will win. Miss Proper and Miss Improper are as capable as any other normal human adult of competent explanatory reasoning, and each knows things, regarding which by far the most plausible explanation is the guilt of Mansour.

Perhaps the intuitive plausibility of $\mathbf{P J}$ derives from the extent to which it overlaps with a deeper principle governing propositional justification. If so, then $\mathbf{P J}$ will have served its purpose in guiding us toward an important insight into the nature of justification.

Here is one suggestion as to what that deeper principle might be. ${ }^{24}$ Judgments about propositional and doxastic justification are moderately idealized, in that they abstract away, to a greater or lesser degree, from the abilities and powers of the specific agent in question, to the abilities and powers manifested in a typical performance by a competent member of the agent's kind. In Ron's case, for example, we have in mind a competent intellectual performance by a normal human adult, who doubtless would be able to competently and ef-

${ }^{23}$ Should the proponent of the extravagant case complain that it would be unusual for someone to reason in this way, I would beg him only to consider how unusual he made poor Ron to begin with.

${ }^{24}$ For a related discussion of "being in a position to know," see Sosa $(1991: 27-29,49)$. 
fortlessly reason his way to the relevant conclusion. This idealized competent performance would then explain why the conclusion is propositionally justified for Ron. The same is true in the cases of Messrs Ponens and Lacy, and Misses Proper and Improper, although we missed the deeper explanation in the latter cases because the subjects in question were capable of competent performances typical of a normal adult human. It is only in Ron's case, where the subject's capabilities diverge significantly from the capabilities of a normal adult human, that the deeper principle suggests itself.

Yet if we idealize to the agent's kind, rather than idealizing to a typical performance of the specific agent in question, it becomes difficult to explain the propositional justification enjoyed by extraordinary humans whose intellectual powers far outstrip the typical human's. Imagine, for instance, that Cedric is the most brilliant logician in the world. Suppose that Cedric is considering whether some proposition, T, is a theorem of some set of axioms, A. T is in fact a theorem of A, and Cedric would normally be able to discover this with ease and in short order, via some clever algorithm he devised. Intuitively, the proposition $<\mathrm{T}$ is a theorem of $\mathrm{A}>$ is propositionally justified for Cedric. However, this cannot be because a typical human adult would be led to that conclusion through competent reasoning, because by hypothesis the logical acumen required to reach that conclusion far exceeds the typical human adult's abilities and powers.

It is possible, then, that the sources of propositional justification are multiple, but in a way that reveals a deeper unity. In cases such as Ron's, where the subject is in some way defective (with respect to the topic at hand, at least), we abstract away from his abilities to those a typical member of his kind. In cases such as Cedric's, where the subject is in some way intellectually extraordinary (again, at least with respect to the topic at hand), our judg- 
ment is guided by the abilities and powers manifested in a typical performance of the subject's own. In either case, though, an idealized competent performance of some agent, closely related to the subject in question, will explain why the subject is propositionally justified.

\section{Conclusion}

In summary, I conclude that the orthodox view of the relationship between propositional and doxastic justification is false. Its failure is instructive, however, pointing the way toward a better understanding of the relationship between those two kinds of justification. The present proposal, which explains propositional justification in terms of doxastic justification, builds on insights gained through a close examination of the orthodox view. If successful, it marks a significant advance in our understanding of the sources of epistemic justification. $^{25}$

\section{Works Cited}

Alston, William. 1985. “Concepts of Epistemic Justification.” Monist, vol. 68. Reprinted in Crumley, ed., 177 - 193.

. 2005. Beyond “Justification”: Dimensions of Epistemic Evaluation. Ithaca: Cornell University Press.

Cohen, Stewart. 1999. "Contextualism, Skepticism, and the Structure of Reasons." Philosophical Perspectives, 13, Epistemology, 1999, 62.

Conee, Earl \& Richard Feldman. 2001. "Internalism Defended." American Philosophical Quarterly 38 (2001): 1-18. Reprinted in Conee \& Feldman 2004. \& _. 2004. Evidentialism: Essays in Epistemology. Oxford: Oxford University Press.

${ }^{25}$ For feedback and discussions that helped improve this paper, I would like to thank Juan Comesaña, Jamie Dreier, Ali Eslami, Derek Ettinger, Ben Fiedor, John Greco, Allan Hazlett, Chris Kane, Jim Pryor, Bruce Russell, Mark Schroeder, Ernest Sosa, Jerry Steinhofer, and James Van Cleve. 
Crumley II, Jack S., ed. 1999. Readings in Epistemology. Mountain View, CA: Mayfield Publishing Co.

Fairweather, Abrol. 2001. “Epistemic Motivation.” In Fairweather \& Zagzebski, eds.

Fairweather, Abrol \& Linda Zagzebski, eds. 2001. Virtue Epistemology: Essays on Epistemic Virtue and Responsibility. Oxford: Oxford University Press.

Feldman, Richard \& Earl Conee. 1985. "Evidentialism.” Reprinted in Sosa \& Kim, eds.

Feldman, Richard. 2002. Epistemology. Upper Saddle River, NJ: Prentice Hall. . 2004. "Foundational Beliefs and Empirical Possibilities." Philosophical Issues, 14, Epistemology, 2004. Reprinted in Conee \& Feldman 2004.

Goldman, Alvin. 1979. "What Is Justified Belief?” Reprinted in Sosa and Kim, eds.

Greco, John. 1999. “Agent Reliabilism.” Philosophical Perspectives, 13, Epistemology, 1999.

. Forthcoming. "Holding Defeat to the Fire."

Harman, Gilbert. 1973. Thought. Princeton: Princeton University Press.

Korcz, Keith. 2000. "The Causal-Doxastic Theory of the Basing Relation." Canadian Journal of Philosophy, vol. 30, no. 4, December 2000, 525 - 550.

Kvanvig, Jonathan. 2003. "Propositionalism and the Perspectival Character of Justification.” American Philosophical Quarterly 40.1 (2003), pp. 3-18.

Lehrer, Keith. 1971. "How Reasons Give Us Knowledge, or the Case of the Gypsy Lawyer. The Journal of Philosophy, vol. 68, no. 10 (May 20, 1971), 311 - 313. . 1990. Theory of Knowledge. Boulder, CO: Westview Press.

Neta, Ram. 2002. "S Knows That P.” Noûs, vol. 36, no. 4, 663 - 681.

Pappas, George S. 1979a. "Basing Relations.” In Pappas, ed. ed. 1979b. Justification and Knowledge. Dordrecht, The Netherlands: D. Reidel Publishing Co.

Pollock, John \& Joseph Cruz. 1999. Contemporary Theories of Knowledge, $2^{\text {nd }}$ ed. New York: Rowman \& Littlefield.

Pryor, James. 2004. "What's Wrong with Moore's Argument?” Philosophical Issues, 14, Epistemology, 2004.

Sosa, Ernest. 1991. Knowledge in Perspective. Cambridge: Cambridge University Press. . 2003. Epistemic Justification: Internalism vs. Externalism, Foundations vs. Virtues (with Laurence BonJour). Malden, MA: Blackwell.

Sosa, Ernest \& Jaegwon Kim, eds. 2000. Epistemology: An Anthology. Malden, MA: Blackwell Publishers.

Swain, Marshall. 1979. “Justification and the Basis of Belief.” In Pappas, ed. 